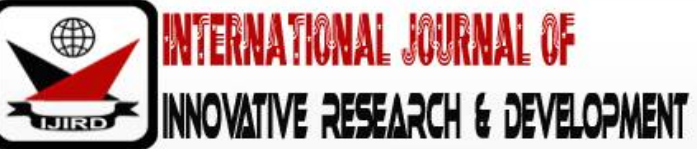

ISSN 2278 - 0211 (Online)

\section{Treatment of Nyabugogo River Water using Chitosan as Flocculant}

Murindababisha David
Postgraduate Student, Department of Chemistry, University of Rwanda, Rwanda
Uwihoreye Vedaste
Postgraduate Student, Department of Chemistry, University of Rwanda, Rwanda
Uzamukunda Cecile
Postgraduate Student, Department of Chemistry, University of Rwanda, Rwanda
Nimukuze Domithile
Postgraduate Student, Department of Accounting, University of Lay Adventist of Kigali, Rwanda

\begin{abstract}
:
Chitosan is a biopolymer, biodegradable, non-toxic and widely abundant in nature. This work presents an investigation on the application of this biopolymer in treatment of Nyabugogo river water by flocculation process. In this study, the raw water from Nyabugogo River characterized by high turbidity was treated using chitosan as flocculant. The performance of this process was evaluated by measuring the supernatant residual turbidity for various values of chitosan concentrations. The obtained results showed that at $\mathrm{pH}$ of 4 , the optimum concentration of chitosan was $160 \mathrm{mg} / \mathrm{L}$. At this concentration, chitosan was able to decrease turbidity from 177 NTU to 5 NTU that is $97.2 \%$ of initial turbidity. The organic carbon contribution on the turbidity coagulation flocculation performance is negligible because chitosan is used in small doses. Hence, chitosan could be used as natural flocculant for Nyabugogo river water treatment with lowest risks of organic release. These properties, combined with its non-toxicity, make the chitosan as the best substitute to conventional synthetic polyelectrolytes used so far.
\end{abstract}

Keywords: River, flocculation, chitosan, turbidity, Rwanda

\section{Introduction}

In the world, industrial development is rapidly causing severe water pollution mostly driven by untreated wastewaters containing different types of dissolved and colloidal contaminants [1], [2].Rwanda is a developing country with about $70 \%$ of the population engaged in agriculture and has undergone rapid industrialization thanks to successful government policy. Since the early-2000s, Rwanda has witnessed an economic boom [3], [4] improving the living standards of many Rwandans. $34.0 \%$ of the population is urban $(4,255,257$ people in 2018). The fertility rate of Rwandans is 5.4 births per woman, and a population growth rate of 2.9 percent based on the latest United Nations estimates.

The population growth and urbanization are clearly linked to industrial development and human activities that are likely to generate pollution. In African countries, Rwanda is one of the most densely populated countries. The capital city, Kigali, is rapidly expanding with increased population growth and industrial development. Kigali is estimated to have the population over 1.2 million people [5].In the city, water quality management has been negatively affected by this expansion, especially wastewater management [6].Rivers passing through the Kigali city such as the Mpazi River and Nyabugogo River have been reported to have high levels of pollution[7], [8]. The Kigali city is situated on the hills and Nyabugogo river passes between those hills therefore all wastewater from City are collected in Nyabugogo river as it is the major outlet of Kigali City.All kinds of untreated wastewaters, including industrial discharges from Kigali city are received by Nyabugogo wetland and wastewater discharged in that river from industrial areas is polluted with heavy metals beyond acceptable environmental standards[9].Mpazi River is a tributary of the Nyabugogo River. It has been reported that wastewater from the Nyabugogo butcher which discharges into Mpazi river and the effluent from that butcher is highly loaded with degradable organics and other pollutants that pose an environmental risk to that river[10].Chemical Oxygen Demand (COD), Biochemical Oxygen Demand (BOD5), nutrients, chloride, calcium, total coliforms and TSS have been identified as the major pollutants from Nyabugogo butcher. Yanze River is another tributary of the Nyabugogo River and it has been reported to have high levels of flooding, erosion, sedimentation and high levels turbidity[11]. [12]studied the assessment of water pollution Levels in the Nyabugogo catchment and he concluded that the Nyabugogo River system is very heavily polluted and turbid river. However, no one reported the treatment of Nyabugogo River water.

Chitosan as a cationic polysaccharide is an important polymer flocculant in water treatment[13], [14].It is a biopolymer, biodegradable, non-toxic, environmentally friendly and widely abundant in nature [15].Chitosanbasedproducts canbe effectively applied for removal of organiccontaminants and hazardous heavy metals such as $\mathrm{Cu}^{2+}, \mathrm{Zn}^{2+}, \mathrm{Ni}^{2+}, \mathrm{Pb}^{2+}$, and $\mathrm{Cr}^{3+}$ 
from wastewaters[16].[17]used chitosan for the treatment of highly turbid water and turbidity was decreased up to less than 10 NTU. [18] Used Chitosan for treatment of Beni-Amrane's high turbid water dam and 97 percent of turbidity was removed then concluded that chitosan could be used as natural coagulant aid for drinking water treatment with lowest risks of organic release.[19] used chitosan as a coagulant in the pre-treatment of turbid sea water.

This research focuses on the treatment of Nyabugogo river water using chitosan as flocculants since they act as a sorbent of salts of heavy metals and other toxic substances for environmental enhancement and maintenance of human health.

\section{Material and Methods}

\subsection{Sample Collection and Description}

Water samples were collected in June 2017 from Nyabugogo River(lat: -01 ${ }^{\circ} 58^{\prime}$, lon: 30 08', and Alt: 1,490.0 m)which is situated in Nyarugenge District, Kigali City(Figure 1). The samples were collected in plastic bottles of 1 liter. Those bottles were rinsed overnight with $1 \mathrm{M} \mathrm{HCl}$ and then with distilled water. They were also rinsed thrice with sample water before final collection. The samples were placed in a cooler box with ice for transportation and then brought to Chemistry Laboratory at University of Rwanda, College of Science and Technology for analysis. Allsamples werestored in a refrigerator at $4^{\circ} \mathrm{Cfor}$ further analyses.

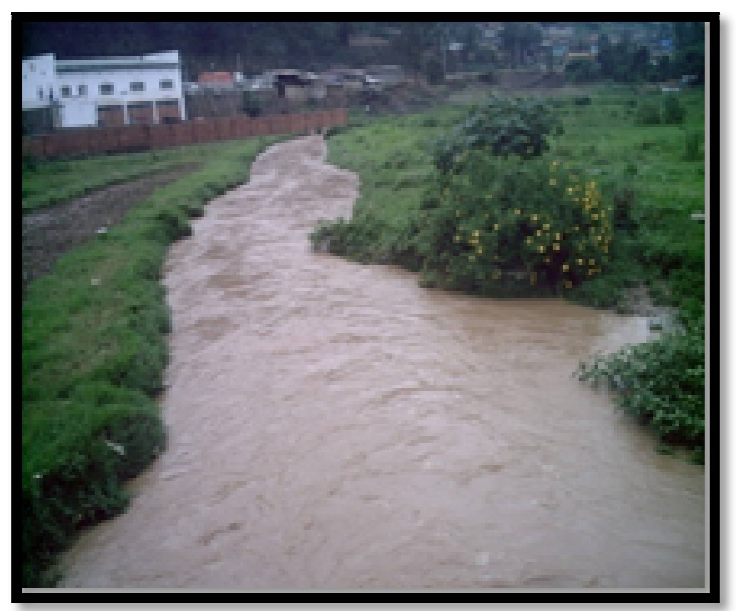

Figure 1: The Sampling Point in Nyabugogo River

\subsection{Chemicals and Reagents}

Chitosan in the form of powder and all other chemicals and reagents were purchased from Sigma-Aldrich, Steinheim, Germay.

\subsection{Flocculant Preparation}

The stock solution of chitosan was prepared before starting the experiment by dissolving $2 \mathrm{~g}$ of each in $100 \mathrm{~mL}$ of distilled water. Chitosan was relatively insoluble; $1 \mathrm{~mL}$ acetic acid solution (1\%) was added to $99 \mathrm{~mL}$ of distilled water before addition of the chitosan powder. The solution was prepared as described by [20].

\subsection{Jar Test Flocculation}

A jar test apparatus (FlocculatorSW6, Mason Technology Ltd, Ireland) was used throughout the coagulation flocculation experiments (Figure 2). It functions as a batch reactor accommodating a series of 6 beakers together with sixspindle stainless steel paddles. The desired $\mathrm{pH}$ of raw water $(4,7$ and 10) was adjusted by adding either acid (1M HCl) or base $(1 \mathrm{M} \mathrm{NaOH})$. Before being distributed into the beakers, the raw water was analyzed. After, the desired concentrations of chitosan $(0,120,160,200,240$ and $280 \mathrm{mg} / \mathrm{L})$ were added to the raw water. This was followed by the rapid mixing $(250$ $\mathrm{rpm}$ ) of the mixture for 1 minute; slow mixing $(40 \mathrm{rpm})$ for 30 minutes and settling for 45 minutes. After settling, the supernatant water was collected using a pipette and analyzed again. All tests were performed at an ambient temperature in the range of 21 and $23^{\circ} \mathrm{C}$. 


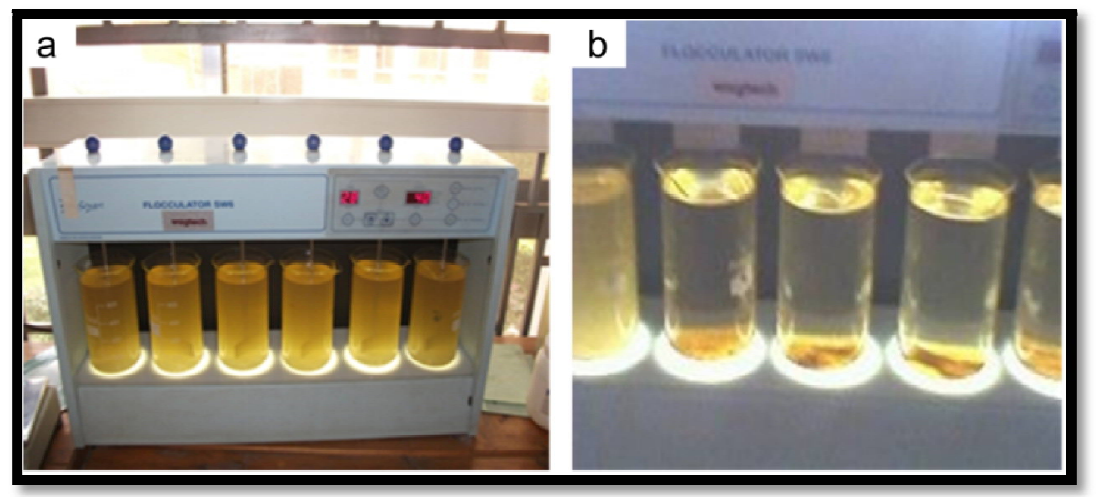

Figure 2: Jar Test Flocculation Before (A) and After (B) Flocculation

\section{5. pH Determination}

The hydrochloric acid and sodium hydroxide were used to adjust the $\mathrm{pH}$ of the water sample at the desired values $(4$, 7 and 10). The $\mathrm{pH}$ was determined using pH-meter (Benchtop pH meter F20 kit,Mettler Toledo, Singapore).

\subsection{Determination of Alkalinity}

The alkalinity test was performed by titration method using $0.02 \mathrm{~N} \mathrm{HCl}$. One hundred milliliters of water sample were poured into $250 \mathrm{~mL}$ conical flask and 2-3 drops of methyl orange indicator was added to the same flask. Titration was performed till yellow colour changed to orange. Finally, the volume of $0.02 \mathrm{~N} \mathrm{HCl} \mathrm{required} \mathrm{was} \mathrm{recorded.}$

\subsection{Determination of Electrical Conductivity (EC) and Total Dissolved Solids (TDS)}

\subsubsection{Electrical Conductivity}

Electrical Conductivity expressed in microsiemens per meter $(\mu \mathrm{S} / \mathrm{m})$ and TDS were determined by using a conductometer (Hanna EC/ TDS/ T0, Mason Technology Ltd, Ireland) after immersing its cleaned electrode into the water sample.

\subsubsection{Determination of Total Suspended Solids (TSS)}

The specific filter paper (Whatman filter papers $1.58 \mu \mathrm{m}$ of size) were dried at $104.5^{\circ} \mathrm{C}-105^{\circ} \mathrm{C}$ for 45 minutes and weighed. By gravimetric methods, the $100 \mathrm{~mL}$ of each taken sample was filtrated using the dried filter paper. The suspended solids were washed by distilled water. The suspended residues were dried on the filter paper containing suspended particles oven for $45-60$ minutes at $104.5^{\circ} \mathrm{C}$. Finally, the obtained solids were weighed using electronic balance and the final results were computed according to the mathematical equation below:

$T S S=\frac{(\text { mass of residues }+ \text { filter after drying }, m g)-(\text { mass of empty dried filter }, m g)}{\text { sample volume, } L}$

\subsubsection{Determination of the Turbidity}

Turbidity was measured by the spectrophotometric method using a turbidimeter (2100 HACH-Turbidimeter, Singapore). The water sample was poured into cells of turbidimeter and the turbidity value was recorded.

\section{Results and Discussion}

3.1. pH Variation from Raw Water to Treated Water

The initial $\mathrm{pH}$ value of raw water samples was 6.84 . The flocculation process was performed after conducting the initial $\mathrm{pH}$ to the desired $\mathrm{pH}$ values $(4,7$ and 10$)$. The results showed that the $\mathrm{pH}$ value gradually increases as the coagulant concentrations increase (Figure 3). This is justified by the electronic cloud present to $\mathrm{NH}_{2}$ group of chitosan molecule.

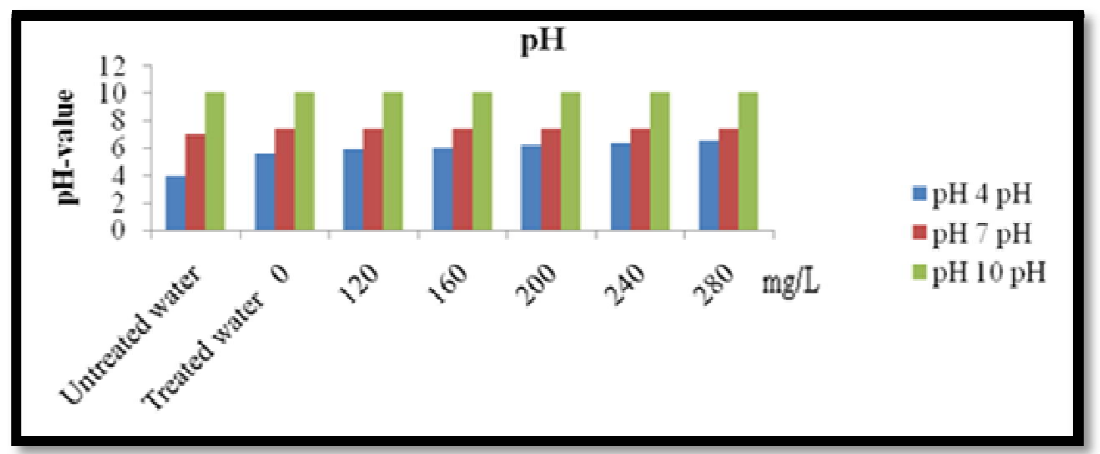

Figure 3: Variation of $\mathrm{Ph}$ in Water Treatment by Using Chitosan 
The $\mathrm{pH}$ would not only affect the surface charge of coagulants, but also the stabilization of the suspension. The functional group of $\mathrm{NH}_{2}$ on chitosan surface has been protonated at $\mathrm{pH} 4$ around $90 \%$, and gradually reduced to about $50 \%$ as $\mathrm{pH}$ increased to 6 [21].Therefore the positive charges on the chitosan surface will significantly decrease as solution $\mathrm{pH}$ increased, so the contribution by the charge neutralization of the chitosan to destabilize the particles becomes less important as $\mathrm{pH}$ increased due to cationic behavior and molecular weight of chitosan.The results showed that chitosan at alkaline $\mathrm{pH}$ shows very low efficiency and required high concentration of chitosan to achieve the required treatment levels [23]. This confirmed that, at least partial, protonation of chitosan amino group was required to achieve efficient coagulation of these organic suspensions.

\subsection{Variation of Alkalinity}

The tests of determining the alkalinity showed that this parameter increased likewise the chitosan dosages. The addition of chitosan to the water sample increased the $\mathrm{pH}$ of water and rendered it more alkaline (Figure 4).

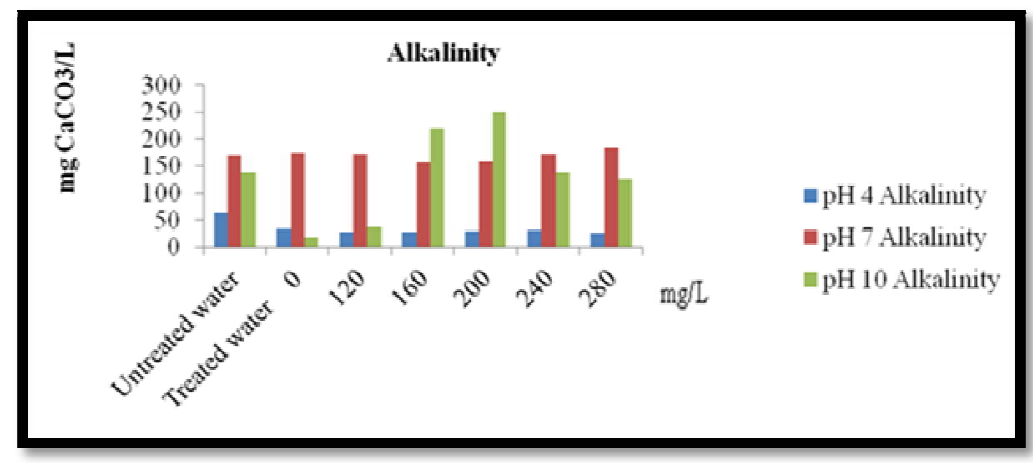

Figure 4: Variation of Alkalinity in Water Treatment by Using Chitosan

\subsection{Variation of Electrical Conductivity (EC)}

It has been observed that the electrical conductivity had been decreased from raw water to the treated water after flocculation process at $160 \mathrm{mg} / \mathrm{L}$ due to the activity of chitosan (Figure 5).

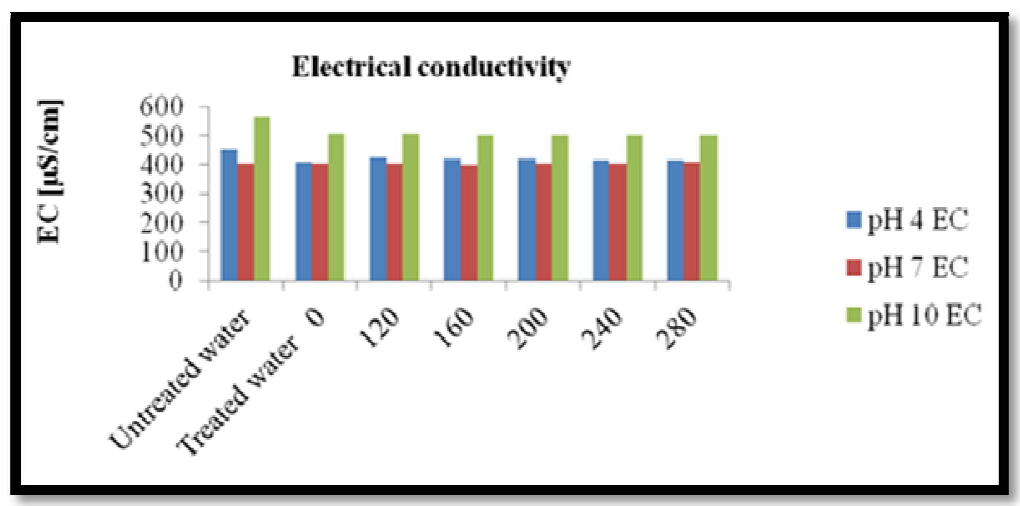

Figure 5: Variation of Electrical Conductivity in Water Treatment by Using Chitosan

3.4. Variation of Total Dissolved Solids (TDS)

The variation of Total Dissolved Solids was affected by the dosages of coagulant as described in the section above (Electrical conductivity). The variation of TDS is directly proportional to the variation of EC.

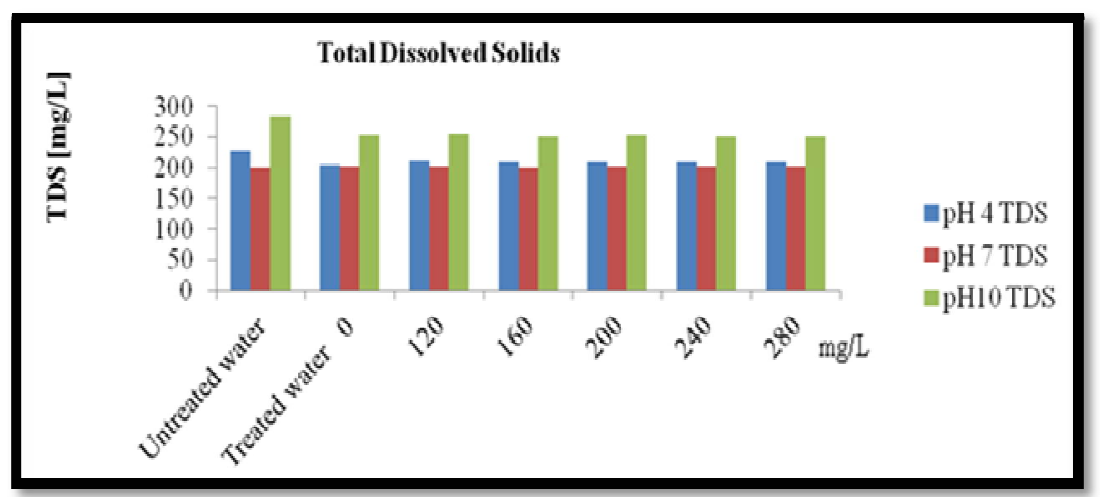

Figure 6: Variation of Total Dissolved Solids in Water Treatment by Using Chitosan 


\subsection{Variation of Total Suspended Solids (TSS)}

The determination of TSS was very important because they are the main solid materials which pollute water. The performance of coagulant was estimated at $160 \mathrm{mg} / \mathrm{L}$. The higher dosages and lower dosages made the coagulants unable for flocculation (Figure7).

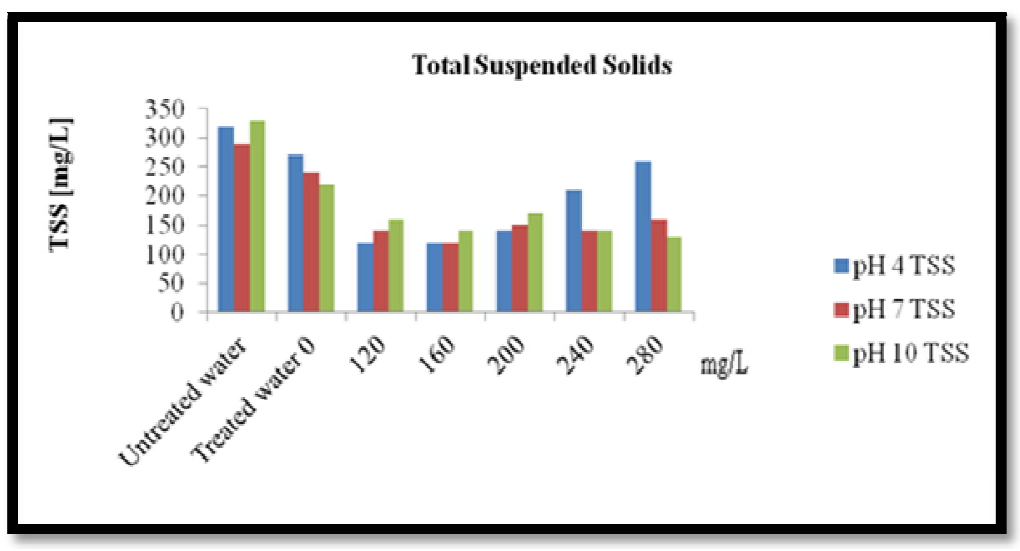

Figure 7: Variation of Total Suspended Solids in Water

Treatment by Using Chitosan

\subsection{Variation of Turbidity}

The results showed the good activity of chitosan at $\mathrm{pH} 4$ where the turbidity decreased at a considerable proportion of $97.2 \%$ by the optimum chitosan concentration of $160 \mathrm{mg} / \mathrm{L}$ (Figure 8). This is confirmed by the protonation of amino functional group responsible for sorption capacity of chitosan. In alkaline conditions, the turbidity did not decrease because the amino group present to chitosan remained neutral.

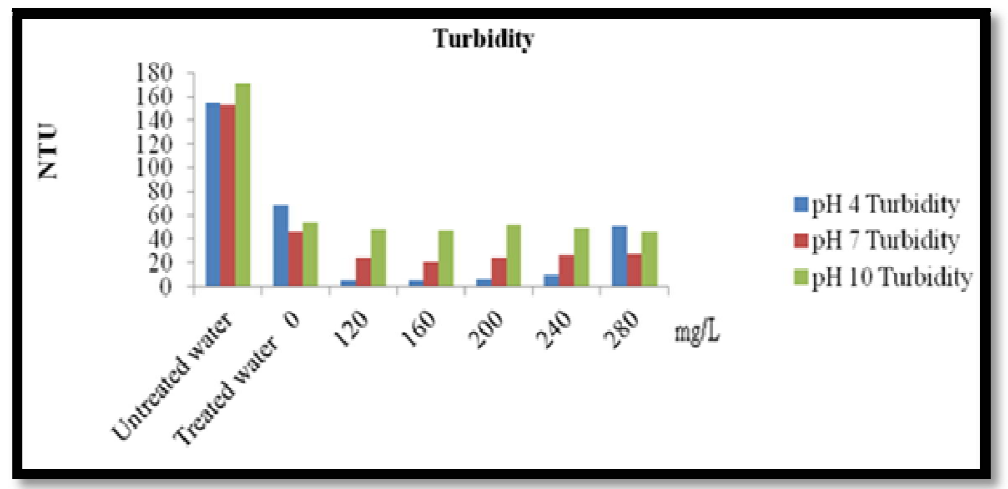

Figure 8: Variation of Turbidity in Water Treatment by Using Chitosan

\subsection{Chitosan Dosages}

Dosage was one of the most important parameters that have been considered to determine the performance of flocculant in coagulation and flocculation process. The effect of dosage was analyzed at pH 4, 7 and 10, mixing rate of 250 rpm for 1 minute and mixing rate of $40 \mathrm{rpm}$ for 30 minutes and 45 minutes of settling time for a range of chitosan dosage which varied from $120 \mathrm{mg} / \mathrm{L}$ to $280 \mathrm{mg} / \mathrm{L}$. The water sample which was adjusted from the initial $\mathrm{pH}$ of 6.84 to $\mathrm{pH} 4$ showed high sorption capacity in flocculation since chitosan is soluble in acidic aqueous phases [23]. Moreover, [21] pointed out that there was $90 \%$ of the functional group of $\mathrm{NH}_{2}$ on chitosan surface has been protonated at $\mathrm{pH}$ 4. Basically, insufficient dosage or overdosing would result in the poor sorption capacity of the coagulant in flocculation process. In contrast, there was a drastic drop for the percentage of reduction for turbidity when the chitosan dosage concentration was in the range of $240 \mathrm{mg} / \mathrm{l}$ to $280 \mathrm{mg} / \mathrm{l}$.

This low sorption capacity was due to the phenomenon of excess polymer which is adsorbed on the colloidal surfaces and producing restabilized colloids. Thus, there were no sites available on the particle surfaces for the formation of interparticle bridges. Then, the restabilized colloidal particles can become positively charged and cause the electrostatic repulsion among the suspended solids. The tests showed that the optimum dosage of chitosan was $160 \mathrm{mg} / \mathrm{L}$.

The dosages did not only affect the sorption capacity of chitosan but also the $\mathrm{pH}$ of the water sample. This is justified by the fact that the increase of chitosan dosages increases the $\mathrm{pH}$ and alkalinity of water sample due to the presence of amino group - $\mathrm{NH}_{2}[16]$.

The table 1 shows the results of parameters before and after treatment by chitosan dosages of $160 \mathrm{mg} / \mathrm{L}$ at $\mathrm{pH} 4$ in comparison with "WHO guidelines". 


\begin{tabular}{|c|c|c|c|}
\hline Parameters & Raw water & Treated water & WHO guidelines \\
\hline $\mathrm{pH}$ & 4.02 & 6.03 & $6.5-8.5$ \\
\hline $\mathrm{EC}(\mu \mathrm{S} / \mathrm{cm})$ & 454 & 421 & $500-1000$ \\
\hline $\mathrm{TDS}(\mathrm{mg} / \mathrm{L})$ & 227 & 210 & $<500$ \\
\hline Turbidity $(\mathrm{NTU})$ & 177 & 5 & 5 \\
\hline $\begin{array}{c}\text { Alkalinity } \\
\left(\mathrm{mgCaCO}_{3} / \mathrm{L}\right)\end{array}$ & 63 & 28 & $80-120$ \\
\hline
\end{tabular}

Table 1: Environmental Parameters Before and After Treatment

The comparison of results with the existing WHO guidelines was basically done after treating the sludge water conducted at $\mathrm{pH} 4$ (acidic conditions). The obtained results are recommended by World Health Organization. The results of $\mathrm{pH}, \mathrm{TDS}$, and turbidity do not exceed the recommended norms of WHO.

\section{Conclusion}

Experiments were conducted to determine the ability of Chitosan as natural flocculant for the treatment of Nyabugogo river water. Through these experiments, it was found that the optimum concentration was $160 \mathrm{mg} / \mathrm{L}$ of chitosan. At this concentration, chitosan was able to decrease turbidity from 177 NTU to 5NTU.It has reduced considerably (97.2\%) turbidity from Nyabugogo River raw water. The chitosan efficiency was highly dependent on initial turbidity and on chitosan dosage. The organic carbon contribution on the coagulation flocculation performance is negligible because chitosan is used in small doses. Hence, chitosan could be used as natural flocculant for Nyabugogo river water treatment with the lowest risks of organic release.Further study on the heavy metals' removal is recommended.

\section{Acknowledgements}

The authors thank University of Rwanda, College of Science and Technology for donating laboratory space. Funding for this project was provided by the University of Rwanda.

\section{References}

i. Shannon,M. A., Bohn, P. W.,Elimelech, M, Georgiadis,J. G., Mariñas, B. J., \&Mayes,A. M. (2008). Science and technology for water purification in the coming decades.Nature,452,301-311.

ii. Pascaline,N., Theophile, M., de Dieu, N. J.,Pauline, M. J.,Claude, N. J., \&PlacideU.(2015).A study on sediments depositional mechanism at Nayakankuppam coast, Tamilnadu, India. International Journal of Engineering Research and General Science, 3, 478-492.

iii. Claude, N. J., \& Pascaline, N. (2015). Concepts of Umutara and Imigongo Colour Based Design in the Traditional Arts of Rwandans and Their Applications in Interior and Fashion Technologies. International Journal of Innovative Research and Development, 4, 334-344

iv. Claude, N. J., \& Pascaline, N. (2015). A Study on Interdependent and Asymmetrical Behaviours Associated with Land use and Land Cover at Ruhande, Huye, Rwanda. International Journal of Innovative Research and Development, 4, 217-222.

v. MINIFRA (2007). Kigali Conceptual Master. http:// www.kigalicity.gov.rw/spip.php?article497. Accessed April, 2017).

vi. Chen,X. J., Zhu, Y. Y.,Shan, X. S., \&Li, W. (2016). The Evaluation of Eutrophication of Tiande Lake. SSRG International journal of Agriculture \& environmental Sciences, 3, 30-34.

vii. Usanzineza, D., Nhapi, I., Wali, U. G., Kashaigili, J. J., \& Banadda, N. (2011). Nutrients inflow and levels in lakes: a case study of Lake Muhazi, Rwanda. Ecol. Develop. Sum, 19, 53-62.

viii. Murindababisha, D.,Havugimana,V., Mutezinka, H.,\&Nimukuze,D. (2018). Performance of Locally Produced Ceramic Pot Filters for Drinking Water Treatment in Rwanda. SSRG International Journal of Applied Chemistry, 5, 10-14.

ix. Nkuranga, E. (2007).Heavy metal removal and accumulation by an Urban Natural Wetland: The Nyabugogo Swamp, Rwanda. MSc Thesis, UNESCO-IHE Institute for Water Education, Delft, The Netherlands.

x. Muhirwa, D., Nhapi, I., Wali, U.G.,Banadda, N., Kashaigili, J.J. \& Kimwaga, R. (2010).Characterisation of wastewater from the Nyabugogo Abattoir, Rwanda and the impact on downstream water quality.Ecol. Develop. Sum,16, 30-46.

xi. Nshimiyimana, A. J. (2008). A comparative assessment of intake systems at Yanze, Kadahokwa, Nyabarongo and Shyogwe water treatments plants. MSc Thesis, National University of Rwanda, Rwanda.

xii. Nhapi, I., Wali, U. G., Uwonkunda, B. K., Nsengimana, H., Banadda, N., \& Kimwaga, R. (2011). Assessment of water pollution levels in the Nyabugogo Catchment, Rwanda. Open Environmental Engineering Journal, 4, 40-53.

xiii. Bertoni, F. A., González, J. C., García, S. I., Sala, L. F., \& Bellú, S. E. (2018). Application of chitosan in removal of molybdate ions from contaminated water and groundwater. Carbohydrate polymers, 180, 55-62.

xiv. Marques, J. S., Pereira, M. R., Sotto, A., \& Arsuaga, J. M. (2019). Removal of aqueous copper (II) by using crosslinked chitosan films. Reactive and Functional Polymers, 134, 31-39.

xv. Yang, R., Li, H., Huang, M., Yang, H., \& Li, A. (2016). A review on chitosan-based flocculants and their applications in water treatment. Water research, 95, 59-89.

xvi. Sarode, S., Upadhyay, P., Khosa, M. A., Mak, T., Shakir, A., Song, S., \& Ullah, A. (2019). Overview of wastewater treatment methods with special focus on biopolymer chitin-chitosan. International journal of biological macromolecules, 121, 1086-1100. 
xvii. Hu, C. Y., Lo, S. L., Chang, C. L., Chen, F. L., Wu, Y. D., \& Ma, J. L. (2013). Treatment of highly turbid water using chitosan and aluminum salts. Separation and Purification Technology, 104, 322-326.

xviii. Zemmouri, H., Drouiche, M., Sayeh, A., Lounici, H., \& Mameri, N. (2013). Chitosan application for treatment of BeniAmrane's water dam. Energy Procedia, 36, 558-564.

xix. Altaher, H. (2012). The use of chitosan as a coagulant in the pre-treatment of turbid sea water. Journal of hazardous materials, 233, 97-102.

xx. Guibal, E., \& Roussy, J. (2007). Coagulation and flocculation of dye-containing solutions using a biopolymer (Chitosan). Reactive and functional polymers, 67, 33-42.

xxi. Soares, S. F., Fernandes, T., Sacramento, M., Trindade, T., \& Daniel-da-Silva, A. L. (2019). Magnetic quaternary chitosan hybrid nanoparticles for the efficient uptake of diclofenac from water. Carbohydrate polymers, 203, 3544 .

xxii. Roussy, J., Van Vooren, M., Dempsey, B. A., \& Guibal, E. (2005). Influence of chitosan characteristics on the coagulation and the flocculation of bentonite suspensions. Water Research, 39, 3247-3258.

xxiii. Soares, S. F., Rodrigues, M. I., Trindade, T., \& Daniel-da-Silva, A. L. (2017). Chitosan-silica hybrid nanosorbents for oil removal from water. Colloids and Surfaces A: Physicochemical and Engineering Aspects, 532, 305-313. 